\title{
PREVALÊNCIA DE LESÕES ORTOPÉDICAS EM ATLETAS DE VAQUEJADA*
}

\author{
ESP. GUDSON GLEYTON QUEIRÓS DE SOUSA \\ Especialista em Terapia da Mão e Membro Superior pela Universidade \\ Federal de São Paulo e Diretor Científico do Instituto da Mão (Alagoas - Brasil) \\ e-mail: gudson.mao@yahoo.com.br \\ ESP. CARLOS HENRIQUE JASMIM BROLLO \\ Especialista em Fisioterapia Traumato-Ortopédica pela \\ Universidade Castelo Branco e Professor da FAL (Alagoas - Brasil) \\ e-mail: carloshbrollo@gmail.com

\section{KAMILLA FEITOSA DE ABREU} \\ Discente de Fisioterapia do Centro Universitário CESMAC (Alagoas - Brasil) \\ e-mail: kamillafabreu@hotmail.com
}

\begin{abstract}
RESUMO
Introdução: A vaquejada é um esporte genuinamente brasileiro, com tradição de mais de 100 anos, e até então não havia conhecimento da prevalência de lesões neste esporte. Materiais e métodos: Foi utilizado um questionário com questões objetivas e subjetivas. Participaram deste estudo 74 atletas, do sexo masculino, com média de idade de 33 anos. Resultados: Foram encontradas 208 lesões nos 74 atletas, perfazendo uma média de 2,8 lesões por atleta. A área mais acometida foi membro superior (75\%), seguido de membro inferior (20\%), tronco (3\%) e cabeça e face (2\%). A lesão de maior prevalência foi entorse com 84 lesões (40\%). Conclusão: A vaquejada está associada ao alto índice de lesão, podendo afastar os competidores por longos períodos.
\end{abstract}

PALAVRAS CHAVE: Traumatismos em atletas; medicina esportiva; prevalência; rodeio (vaquejada).

Agradecemos ao Prof. Dr. Euclídes Maurício pelo auxílio na estatística desse periódico, ao Prof. Dr. Carlos Brandt pela revisão e ao amigo Dr. Rui Ferreira pelas dicas apresentadas nos momentos precedentes à realização das entrevistas. 


\section{INTRODUÇÃO}

A vaquejada é um esporte genuinamente brasileiro, com tradição de mais de 100 anos. Nos últimos dez anos vem se modernizando e profissionalizando. Apesar de se concentrar nas regiões Norte, Nordeste e Centro-Oeste, atualmente são realizadas mais de 1.000 vaquejadas por ano em todo Brasil (MARIA, 2009). Os participantes concorrem até três vezes por semana e viajam vários quilômetros a procura de eventos.

A vaquejada é uma modalidade esportiva regulamentada pela Lei Federal 4.495/98, bem como a profissão de "vaqueiro" pela Lei n 10.220 de onze de abril de 200 I, que considera atleta profissional o "peão de vaquejada" (CONGRESSO NACIONAL DA REPÚBLICA DO BRASIL, 2001 ; MARIA, 2009).

Um evento dura cerca de três dias com o atleta chegando a competir dezenas de vezes. As exigências do esporte são breves e intensas, exigindo esforços máximos do atleta durante períodos curtos. Neste, como na maioria dos esportes equestres, existe a imprevisibilidade do acidente, e a capacidade do cavalo de se deslocar em velocidades de até 75 km por hora, com a cabeça do cavaleiro a uma distância aproximada de três metros do solo, criam oportunidade de lesão séria(BALL et al., 2009).

As corridas são praticadas por dois atletas, que montados em seus cavalos perseguem pela pista um boi que frequentemente sai em velocidade do curral e tentam derrubá-lo dentro da demarcação feita na pista, normalmente com dez metros de largura (ABQM, 2005; CAMPEV, 2009).

Uma corrida dura cerca de doze segundos, a depender das dimensões da pista, manejo do boi pelos atletas e velocidade dos animais.

Cada "vaqueiro" tem uma função específica. $\bigcirc$ esteira é o encarregado de posicionar o boi da melhor forma na pista, pegar e entregar rapidamente a cauda do boi para seu companheiro. Após a queda do boi na faixa, esse atleta, em seu cavalo, tem a responsabilidade de não permitir que o bovino, ao se levantar, ultrapasse a demarcação (ABQM, 2005; CAMPEV, 2009).

O puxador é o responsável por puxar o boi pela cauda e derrubá-lo dentro da demarcação feita na arena. Para boa fixação da cauda do boi no punho do vaqueiro, este utiliza-se de um peculiar equipamento, chamado "luva de vaquejada". Esta é confeccionada de couro e possui correias que a prendem ao punho do atleta fortemente (ABQM, 2005).

A "luva" possui uma proeminência na sua parte superior, que posicionada no atleta se encontra na região distal do rádio e ulna. Este no momento da derrubada estará com a cauda do bovino laçada no punho e segurando com a mão cerrada (figura I)'.

I. Todas as fotografias e desenhos presentes neste manuscrito são de autoria dos próprios autores. 


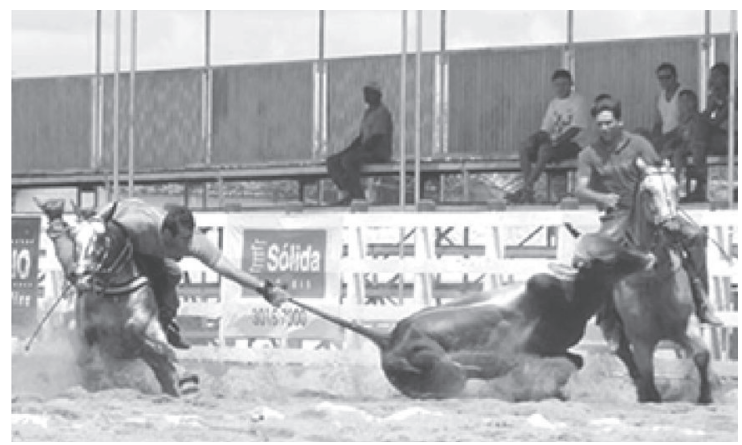

Figura I. Derrubada do boi

Os cavalos montados pelos atletas percorrem a pista em velocidade, e não raramente observam-se atletas caírem de seus animais violentamente (figura 2 e 3). O membro superior do puxador sofre intenso estresse predispondo a lesões, visto que o atleta tenta derrubar o boi que pode pesar mais de $300 \mathrm{~kg}$.

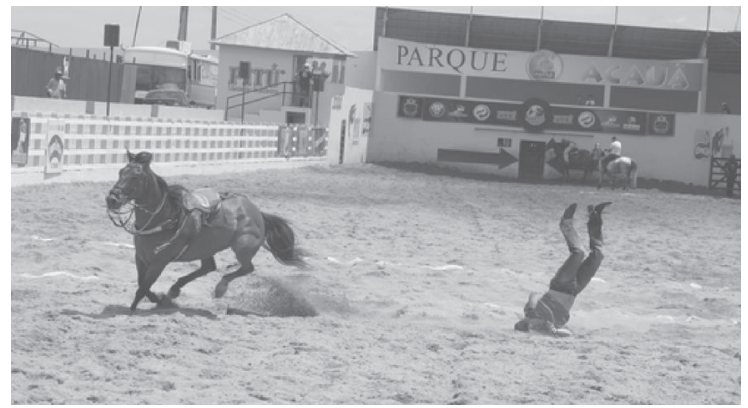

Figura 2. Acidente com risco iminente de lesão

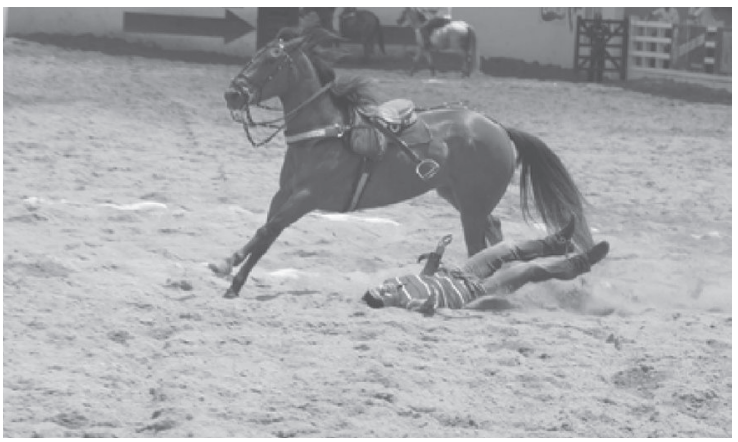

Figura 3. Queda após a derrubada do boi 
Embora existam estudos internacionais sobre lesões ortopédicas associadas a esportes praticados com cavalos (BUTTERWICKAND MEEUWISSE, 2002; CRIDDLE, 200 I; CUENCA et al., 2009; DOWNEY, 2007; LODER, 2008; NELSON and BIXBY-HAMMETT, I 992; NEWTON and NIELSEN, 2005; THOMAS et al., 2006; THOR, 2003; WATT and FINCH, 1996), não se encontrou sondagens sobre estas injúrias associadas à prática da vaquejada. Portanto, este estudo se fez necessário e é pioneiro neste aspecto, iniciando uma busca rigorosa de quais são as lesões mais frequentes no esporte e suas consequências na vida esportiva e diária do atleta.

\section{MATERIAIS E MÉTODOS}

O estudo foi aprovado pelo Comitê de Ética em Pesquisa da FCBS/CESMAC (CEP 659/09). Todos os participantes foram previamente esclarecidos sobre os objetivos e procedimentos referentes à pesquisa e assinaram um termo de consentimento livre e esclarecido, concordando em participar.

Participaram deste estudo setenta e quatro atletas, do sexo masculino, com média de idades de $33 \pm 9$ anos. Os indivíduos foram abordados durante a $I^{\circ}$ Etapa do Circuito Pernambucano de Vaquejada no Parque de Vaquejada SOVACA - PE e a Vaquejada do Parque Lucas Madeiro - AL, em abril de 2009. O instrumento utilizado para coleta de dados foi um questionário com questões objetivas e subjetivas, no qual foram coletados dados referentes às iniciais do nome do atleta, idade, sexo, categoria, posicionamento, tempo de prática esportiva, prevalência de lesões nos últimos vinte e quatro meses de atuação, tempo de afastamento, mecanismo de lesão, segmentos corpóreos mais acometidos, tipo de lesão e utilização de materiais de proteção individual. Os critérios de inclusão foram atletas de vaquejada profissionais e amadores (puxadores e/ou esteiras) com idade entre 18 e 65 anos, que pratiquem a modalidade esportiva há pelo menos cinco anos e com frequência de no mínimo um treino ou competição por semana. Foram excluídos os atletas da categoria aspirante.

A amostra foi de conveniência no período de estudo. Os resultados foram expressos por suas frequências. As variáveis contínuas foram expressas por suas médias e desvios padrão. Quando o grau de dispersão era alto, foi usado o erro padrão da média como medida do grau de dispersão.

Foi utilizado o teste Qui-Quadrado para avaliação de possíveis diferenças entre frequências. Os dados foram analisados utilizando o programa BioEstat 5.0. O nível de significância fixado foi de $p<0,05$.

\section{RESULTADOS}

Entre os entrevistados 50 (68\%) eram da categoria amador e 24 (32\%) profissionais, com média de tempo de prática esportiva de 13,0 \pm 6,7 anos, 
e mediana de 13 anos. Dos questionados, 15 (30\%) atuam na posição de puxador, I ( I\%) esteira e 58 (79\%) em ambas. Foram encontradas 208 lesões nos 74 atletas, perfazendo uma média de 2,8 lesões por atleta em um período de 24 meses. Os locais mais afetados estão expressos em frequências absoluta e relativa.

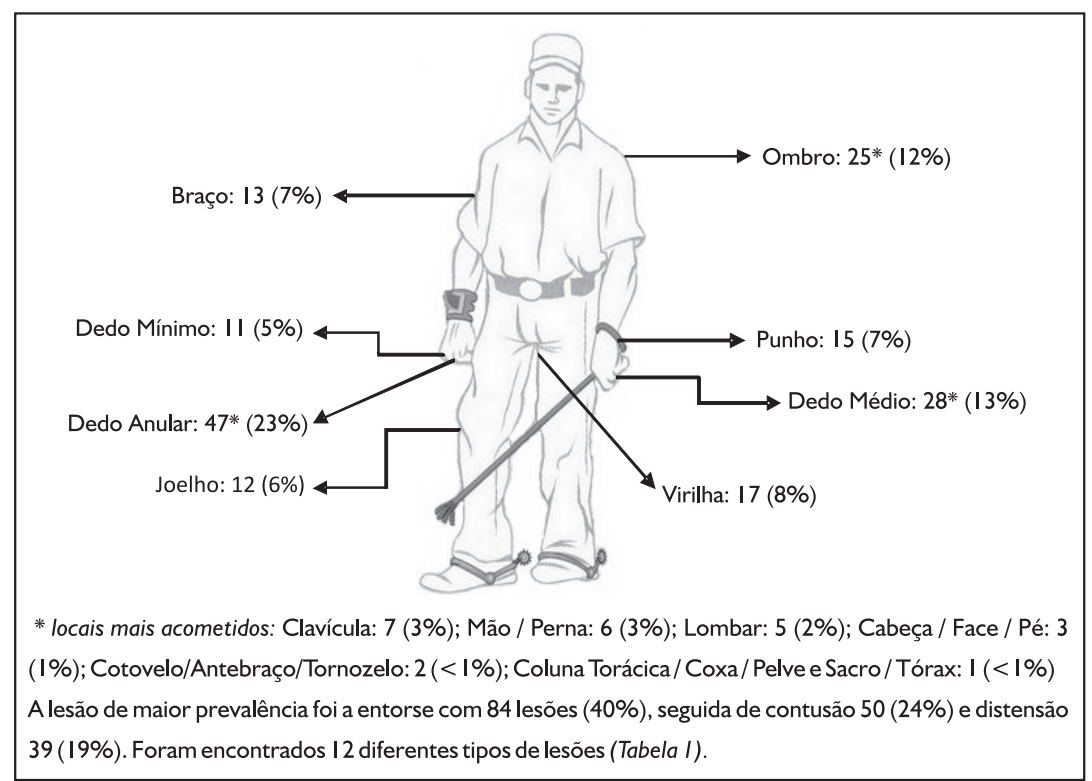

Figura 4. Distribuição das injúrias em Atletas de Vaquejada.

Tabela I. Tipos de Lesões em Atletas de Vaquejada.

\begin{tabular}{lcc}
\hline Tipo de Lesões & Lesões & $\%$ \\
\hline Entorse & 84 & $40 \%$ \\
Contusão & 50 & $24 \%$ \\
Distensão & 39 & $19 \%$ \\
Fratura & 18 & $9 \%$ \\
Luxação / Subluxação & 8 & $4 \%$ \\
Escoriação & $\mid$ & $<1 \%$ \\
Lombalgia / Cervicalgia & $\mid$ & $<1 \%$ \\
Tendinopatia & $\mid$ & $<1 \%$ \\
Cortocontusa & $\mid$ & $<1 \%$ \\
Choque com Perda de Consciência & $\mid$ & $<1 \%$ \\
Lesão Ligamentar com instabilidade & $\mid$ & $1 \%$ \\
Outros & 3 & \\
\hline
\end{tabular}


Das entorses, $51 \%$ incidiram no dedo anular e 30\% no dedo médio. Em relação às contusões $30 \%$ ocorreram no punho enquanto $22 \%$ acometeram o joelho. Já as distensões estavam presentes em $43 \%$ das lesões ocorridas na virilha e em $30 \%$ no braço.

Nas lesões de ombro 40\% foram ocasionadas por contusão e 32\% por distensão muscular, acometendo exclusivamente a musculatura peitoral com 100\% dos casos. Enquanto que as lesões de bíceps braquial representaram 93\% de todas as distensões no braço.

A média dos tempos de afastamento dos atletas foi de 37,5 \pm 8,6 dias (Média \pm Erro Padrão da Média). Foi observada grande discrepância entre o período de afastamento dos atletas em diferentes tipos e gravidades das injúrias. A maior parte dos atletas relata que só interromperam as montarias quando a dor era muito grande, seus ferimentos graves ou se houvesse situação que envolvesse risco de vida.

Quando se investigou a associação dos locais de lesões, tipos e afastamento da prática esportiva por mais de trinta dias, a injúria no dedo mínimo, causada por entorse mostrou-se com maior índice de afugentamento (50\%), provavelmente pela maior importância da lesão. (Tabela 2)

Tabela 2. Correlação entre local de lesão, tipo e afastamento da prática esportiva.

\begin{tabular}{|c|c|c|c|}
\hline Locais & Indivíduos & Tipo (\%) & afastamento > que 30 dias* \\
\hline Dedo Anular & 47 & Entorse $(9 \mid \%) \dagger$ & $25 \%$ \\
\hline Dedo Médio & 28 & Entorse $(92 \%) \dagger$ & $26 \%$ \\
\hline Ombro & 25 & Contusão (40\%) & $10 \%$ \\
\hline Virilha & 17 & Distensão (I 00\%)† & $35 \%$ \\
\hline Punho & 15 & Contusão (I00\%)† & $0 \%$ \\
\hline Braço & 13 & Distensão (92\%)‡ & $16 \%$ \\
\hline Joelho & 12 & Contusão (9|\%)§ & $9 \%$ \\
\hline Dedo Mínimo & 11 & Entorse (9|\%)‡ & $50 \%$ \\
\hline
\end{tabular}

* porcentagem de afastamento de cada lesão específica impedindo a atividade esportiva.

$\dagger p<0.0001 \neq p<0.005 \S p<0.009$

Observou-se que $100 \%$ das lesões ocorridas no $3^{\circ}, 4^{\circ}$ e $5^{\circ}$ quirodáctilos foram causadas pelo mecanismo de desvio ulnar dos dedos. Segundo relato dos atletas envolvidos neste tipo de lesão, este fato ocorre no momento em que o puxador finaliza o movimento da derrubada do boi, havendo um deslocamento medial dos dedos, predispondo a esta lesão. Outro mecanismo bastante frequente e que envolve risco de lesões graves é a queda dos atletas do cavalo (Tabela 3). 
Tabela 3. Diferentes mecanismos lesionais em atletas de Vaquejada.

\begin{tabular}{lll}
\hline Mecanismo de Lesão & Quantidade & $\%$ \\
\hline Desvio ulnar dos dedos durante a puxada do boi & 89 & $43 \%$ \\
Queda do cavalo & 27 & $13 \%$ \\
Tracionamento de membro superior durante a puxada do boi & 26 & $13 \%$ \\
Contusão causada pela Luva & 16 & $8 \%$ \\
Contusão no boi & 13 & $6 \%$ \\
Abdução brusca de quadril durante a saída de sela & 12 & $5 \%$ \\
Queda com o cavalo & 10 & $5 \%$ \\
Abdução brusca de quadril durante a frenagem do boi & 7 & $3 \%$ \\
Contusão na estaca & 5 & $2 \%$ \\
Hiperextensão lombar & 2 & $<1 \%$ \\
Rotação lateral da tíbia & 1 & $<1 \%$ \\
\hline
\end{tabular}

Os resultados apontam que das lesões ocorridas por queda do cavalo, em $41 \%$ dos casos houve contusão, 22\% luxação e 19\% fraturas, destas $60 \%$ foram de clavícula e $20 \%$ de antebraço e braço cada, afastando os atletas das competições por em média 69 dias

Foi observado que dezessete atletas (23\%) não utilizaram nenhum equipamento de proteção individual durante a competição. No entanto, 36\% faziam uso de capacete, $29 \%$ protetor de luva e 12\% perneira.

\section{DISCUSSÃO}

A vaquejada é uma modalidade esportiva muito difundida, principalmente no Nordeste, atraindo milhares de participantes. Até então este esporte não apresentava dados epidemiológicos que descrevessem o perfil dos atletas e a prevalência de lesões. Este artigo tem a responsabilidade de trazer dados científicos e pioneiros quanto à frequência, localização, gravidade e os mecanismos que predispõem as lesões nessa peculiar modalidade equestre.

Na população estudada os acidentes causados pela prática da vaquejada foram frequentes. $O$ cavalo é um animal com características que lhe conferem certo potencial lesivo, e este é aumentado quando se associa corridas em que o montador tem que dominar o cavalo ao mesmo tempo em que tenta derrubar o boi que pode pesar mais de $300 \mathrm{~kg}$.

Atividades equestres são consideradas, por alguns, como esporte de alto risco (CUENCA et al., 2009). Andar a cavalo é mais perigoso que corridas automobilísticas, esqui, futebol e rugby (BALL et al., 2009).

Na vaquejada os atletas puxadores estão constante e repetidamente submetendo as articulações dos membros superiores a grandes forças de tração, o que parece predispor este segmento a lesões por overuse (esforço repetitivo). 
Relato da ocorrência de lesões labrais antero-superiores, com frequência próxima de 10\% de rupturas parciais do bíceps em atletas submetidos à tração repetitiva, do membro superior, foram descritas por Andrews et al., 1985. Nos nossos resultados $6 \%$ das lesões totais encontradas no membro superior foram causadas por distensão no bíceps braquial, sendo este músculo responsável por 96\% de todas as distensões incididas no braço. A partir disto observa-se uma clara relação entre as forças de tração do membro superior durante a derrubada do boi e o episódio de lesões no bíceps braquial.

Nos Estados Unidos da América, dados demográficos de lesões causadas por quedas em atividades equestres (LODER, 2008) se assemelham aos resultados descritos neste estudo. Os saldos mostram que as quedas podem gerar desde escoriações leves, até fraturas de maior gravidade acometendo em maior proporção a clavícula e o antebraço afastando o atleta em média 69 dias.

Como citado anteriormente, $100 \%$ das lesões de $3^{\circ}, 4^{\circ}$ e $5^{\circ}$ quirodáctilos foram originadas do mecanismo de desvio ulnar dos dedos. Há fortes indícios com base no relato dos atletas que esta lesão ocorra em decorrência do desvio ulnar dos dedos provocado pelo rabo do boi no momento da puxada.

Quando se averiguou a associação dos sítios de lesões, tipos e afastamento da prática esportiva foi observado que a lesão no dedo mínimo, causada por entorse apresenta o maior índice de afugentamento, em cerca de 50\%.

Na presente pesquisa, foi observado que uma parcela considerável (39\%) dos atletas não fazem o uso de capacete durante as competições, e (23\%) não utilizam nenhum equipamento de proteção, fato considerado de extrema importância. Sabe-se que o capacete é um equipamento que pode fazer a diferença com relação à gravidade da lesão quando esta acomete a cabeça. Talvez a ausência deste simples equipamento possa influenciar negativamente as lesões causadas por traumatismos cranianos.

As quedas são relativamente frequentes na vaquejada, representando o segundo mecanismo lesional mais comum. Na maioria das vezes acomete o atleta puxador quando o boi diminui abruptamente a velocidade e o cavaleiro está com a mão laçada em seu rabo e não consegue se desvencilhar rapidamente, ou mais frequentemente no momento da puxada do boi quando o atleta não se mantém firme em cima do cavalo devido ao grande peso do boi ou a um desequilíbrio gerado durante a puxada.

Grande parte dos atletas que praticam vaquejada está disposto a continuar se exercitando com dor, relatando só interromper a prática esportiva quando o 
próprio considera a lesão grave ou quando há risco de vida, o que torna a prática esportiva muito preocupante nestas condições.

O presente manuscrito tem o papel de apresentar dados epidemiológicos dos riscos de lesões associadas à prática da vaquejada e a partir disto chamar a atenção de atletas por meio das federações e associações quanto às medidas de proteção que podem ser adotadas para minimizar os riscos de lesões graves. Em especial a conscientização da utilização do capacete para prevenir os traumatismos cranioencefálicos frequentes em atividades equestres em geral (GHOSH et al., 2000; MCCRORY; TURNER, 2005).

A análise dos resultados sugere que é necessário alertar a população sobre os riscos que envolvem a vaquejada e estimular campanhas preventivas e informativas na tentativa de evitar ou minimizar a ocorrência de lesões neste esporte. Programas de prevenção de acidentes devem ser implementados tanto para os atletas como para os animais. $\bigcirc$ uso de equipamentos de proteção e a educação dos atletas podem propiciar uma vaquejada com menos riscos de acidentes, tornando esse esporte uma prática mais segura.

\section{CONCLUSÃO}

A vaquejada apresentou altos índices de lesões na população estudada, por vezes afastando os competidores por longos períodos. Devido à ausência de trabalhos realizados nesse tipo de esporte o presente estudo demonstra dados importantes e pioneiros com relação ao perfil epidemiológico do esporte em questão. Esta pesquisa pode fornecer um rumo para elaboração de programas de caráter preventivo e orientação aos atletas e profissionais envolvidos neste esporte.

\section{Prevalence of orthopedic injuries in athletes of rodeo brazilian (vaquejada)}

ABSTRACT: Introduction: The Brazilian rodeo (vaquejada) is a genuinely native sport, with a tradition of more than 100 years, and until then there was no knowledge of the prevalence of injuries in this sport. Materials and methods: The instrument used for data collection was a questionnaire with subjective and objective questions. The study included 74 athletes, male, mean age of 33. Results: It was found 208 injuries in 74 athletes, with mean of 2.8 injuries per athlete. The area most affected was the upper limb (75\%), followed by lower limb (20\%), trunk (3\%) and head and face (2\%). The highest prevalence of injury was sprain with 84 lesions. Conclusion: The vaquejada is associated with a high rate of orthopedic injury and may exclude competitors for long periods of time.

KEY WORDS: Athletic injuries; sports medicine; prevalence; brazilian rodeio (vaquejada). 


\section{La prevalencia de lesiones ortopédicas en los atletas de vaquejada}

RESUMEN: Introducción: vaquejada es un deporte de tradición genuinamente brasileña, con más de 100 años, y hasta entonces no había conocimiento de la prevalencia de las lesiones en este deporte. Materiales y métodos: Se utilizó un cuestionario con el objetivo y subjetivo. 74 atletas participaron en este estudio fueron del sexo masculino, edad media 33 años. Resultados: Hubo 208 lesiones en 74 atletas, haciendo un promedio de 2,8 lesiones por cada atleta. La zona más afectada fue el miembro superior (75\%), seguido de las extremidades inferiores (20\%), el tronco (3\%) y cabeza y la cara (2\%). La lesión más prevalente fue la esguince con 84 lesiones (40\%). Conclusión: vaquejada se asocia con altas tasas de lesiones y pueden evitar los competidores por largos periodos.

PARABLAS CLAVE: Traumatismos en atletas; medicina deportiva; prevalencia; rodeo.

\section{REFERÊNCIAS}

ABQM. Regulamento Geral de Vaquejada do Ano 2005. In: Associação Brasileira de Criadores de Cavalo Quarto de Milha. v. 8. São Paulo: ABQM, 2005.

ANDREWS, J. R.; CARSON, W. G.; MCLEOD, W. D. Glenoid labrum tears related to the long head of the biceps. Am J Sports Med, v. I3, p. 337-34I, 1985.

BALL, J. E. et al. Ten years of major equestrian injury: are we addressing functional outcomes? J Trauma Manag Outcomes, v. 3, p. 2, 2009

BUTTERWICK, D. J.; MEEUWISSE, W. H. Effect of experience on rodeo injury. Clin J Sport Med, v. 12, p. 30-5, 2002.

CAMPEV. Regulamento do Campeonato Pernambucano de Vaquejada. In: Congresso Nacional da República do Brasil. Casa Civil, Subchefia para assuntos jurídicos, Lei n. 10.220, II de abril de 200 I. Brasília, 200 I.

CRIDDLE, L. M. Livestock trauma in central Texas: cowboys, ranchers, and dudes. J Emerg Nurs, v. 27, p. |32-40, 2001.

CUENCA, A. G. et al. Equestrian injuries in children. J Pediatr Surg, v. 44, p. 148-50, 2009 .

DOWNEY, D. J. Rodeo injuries and prevention. Curr Sports Med Rep, v. 6, p. 328-32, 2007.

GHOSH, A. et al. Horse-related injuries in pediatric patients. J Pediatr Surg, v. 35, p. I 766 70, 2000.

LODER, R. T. The demographics of equestrian-related injuries in the United States: injury patterns, orthopedic specific injuries, and avenues for injury prevention. J Trauma, v. 65, p. 447-60, 2008. 
MARIA, J. Vaquejada em Petrolina: um sucesso absoluto. Revista Conexão Vaquejada, v. 33, p. 28-29, 2009.

MCCRORY, P.; TURNER, M. Equestrian injuries. Med Sport Sci, v. 48, p. 8- I7, 2005.

NELSON, D. E.; BIXBY-HAMMETT, D. Equestrian injuries in children and young adults. Am J Dis Child, v. 146, p. 61 I-4, 1992.

NEWTON, A. M.; NIELSEN, A. M. A review of horse-related injuries in a rural Colorado hospital: implications for outreach education. J Emerg Nurs, v. 3I , p. 442-6, 2005.

THOMAS, K. E. et al. Non-fatal horse related injuries treated in emergency departments in the United States, 200I-2003. Br J Sports Med, v. 40, p. 619-26, 2006.

THOR, J. Realities of rodeo. Lancet, v. 362 Suppl, p. 52-53, 2003.

WATT, G. M.; FINCH, C. F. Preventing equestrian injuries. Locking the stable door. Sports Med, v. 22, p. 187-97, 1996.

Recebido: 13 jun. 2010

Aprovado: 04 jan. 2011

Endereço para correspondência: Gudson Gleyton Queirós de Sousa Rua Pref. Abdon Arroxelas, 657, Apto. 805 - Bairro Ponta Verde Maceió - AL CEP: $57.035-380$ 